\title{
Análise do índice de saturação por sódio em latossolo vermelho fertirrigado com efluente de laticínios
}

Objetivou-se com este estudo, avaliar o impacto que o sódio presente nos efluentes de laticínios podem acarretar na variação do índice de saturação por sódio (ISNa) em latossolo vermelho fertirrigado. Para se obter essas informações, montou-se um experimento formado por cinco tratamentos com quatro repetições plantados com capim Panicum maximum. Os tratamentos foram formados de acordo com as concentrações de sódio, fornecendo: 75; 150; 300 e 600 kg ha-1 de $\mathrm{Nat;}$ e um tratamento testemunha com água de irrigação. Amostras de solo foram coletas nas profundidades de 0-10, 10-20, 20-30 e 90-100 cm para as análises. Os cátions trocáveis foram obtidos através de fotometria de chamas e absorção atômica, os valores de ISNa foram obtidos por meio de cálculos que envolveram esses cátions. Os resultados obtidos demonstraram que os solos analisados podem receber efluente de laticínios com concentrações até $600 \mathrm{~kg}$ ha-1 sem sofrer sanilização siginficativa.

Palavras-chave: Agropecuária; Sódio; Reuso; Capim-mombaça; Produtividade.

\section{Analysis of the sodium saturation index in red fertirrigated latosil with dairy effluent}

\begin{abstract}
The purpose of this study was to evaluate the impact that sodium in dairy effluents can have on the variation of the sodium saturation index (ISNa) in fertirrigated red latosol. To obtain this information, an experiment was set up consisting of five treatments with four repetitions planted with Panicum maximum grass. The treatments were formed according to the sodium concentrations, providing: 75; 150; 300 and $600 \mathrm{~kg} \mathrm{ha}-1$ of Na+; and a control treatment with irrigation water. Soil samples were collected at depths of 0-10, 10-20, 20-30 and 90-100 cm for analysis. The exchangeable cations were obtained through flame photometry and atomic absorption, the ISNa values were obtained through calculations involving these cations. The results showed that the analyzed soils can receive dairy effluent with concentrations up to $600 \mathrm{~kg}$ ha-1 without undergoing significant sanilização.
\end{abstract}

Keywords: Agriculture; Sodium; Reuse; Mombasa grass; Productivity.

Topic: Engenharia Agrícola

Reviewed anonymously in the process of blind peer
Received: 07/08/2020

Approved: 18/09/2020
Paulo Tárcyo de Resende Teixeira (it Instituto Federal Goiano, Brasil http://lattes.cnpq.br/3582835679798961 http://orcid.org/0000-0003-4898-6457 paulotarcyo@hotmail.com

Jose Antônio Rodriguez de Souza (ic Instituto Federal Goiano, Brasil http://lattes.cnpq.br/1637300776838940

http://orcid.org/0000-0003-3024-9424 jose.antonio@ifgoiano.edu.br

Débora Astoni Moreira (iD)

Instituto Federal Goiano, Brasil

http://lattes.cnpq.br/0892554192927049

http://orcid.org/0000-0002-8658-1269

debora.astoni@ifgoiano.edu.br

Walisson Marques Oliveira
Instituto Federal Goiano, Brasil
http://lattes.cnpq.br/7052217868475846
$\frac{\text { http://orcid.org/0000-0002-4615-8335 }}{\text { walissonmo.msn@hotmail.com }}$
Éllen Lemes Silva (1D
Instituto Federal Goiano, Brasil
http://lattes.cnpq.br/2020996967548069
http://orcid.org/0000-0001-5649-5055
ellen cbba@hotmail.com
Diego César Veloso Rezende 10
Instituto Federal Goiano, Brasil
http://lattes.cnpq.br/2390623769547865
http://orcid.org/0000-0001-6176-0220
diegoformiga@yahoo.com.br

Wesley Anderson Siqueira Ribeiro (ID) Instituto Federal Goiano, Brasil http://lattes.cnpq.br/4063527816946300 http://orcid.org/0000-0003-4056-9798 wesleyk13anderson@hotmail.com
Referencing this:

TEIXEIRA, P. T. R.; SOUZA, J. A. R.; MOREIRA, D. A.; OLIVEIRA, W. M.; SILVA, É, L.; REZENDE, D. C. V.; RIBEIRO, W. A. S.. Análise do índice de saturação por sódio em latossolo vermelho fertirrigado com efluente de laticínios. Revista Ibero Americana de Ciências Ambientais, v.11, n.5, p.83-89, 2020. DOI: http://doi.org/10.6008/CBPC2179$\underline{6858.2020 .005 .0009}$ 


\section{INTRODUÇÃO}

A indústria de laticínios representa uma atividade de grande importância na economia brasileira e mundial, não apenas devido ao volume de oferta e geração de divisas, mas também pela composição na dieta alimentar humana. O Brasil é um grande produtor de leite e possui condições para se tornar um dos maiores exportadores de produtos lácteos devido às suas vantagens, tais como disponibilidade de água, terra e custo de produção competitivo.

No entanto, trata-se de uma atividade que consome muita água e gera grande quantidade de efluentes, cujos volumes dependem do tipo de processo utilizado, dos produtos produzidos, da qualidade da água requerida e das práticas de gestão aplicadas (VOURCH et al., 2008). Segundo Saraiva et al. (2009), a relação entre o volume de leite processado e o volume de efluente gerado, chamada de coeficiente volumétrico de efluente líquido, é de aproximadamente 3,5 litros de efluente por litro de leite processado.

Conforme descrito por Braile et al. (1993), os efluentes líquidos (águas residuárias) contêm quantidades variadas de matéria-prima diluída, apresentando elevados teores de matéria orgânica, gorduras, sais, sólidos suspensos e nutrientes, além da eventual presença de organismos patogênicos (CATÃO et al., 2000), sendo esses efluentes líquidos considerados a principal fonte de poluição dessas indústrias.

Diversos problemas têm sido relatados durante o tratamento convencional desses efluentes, que normalmente inclui tratamento primário para remoção de sólidos suspensos e gorduras e, tratamento secundário biológico. Esses problemas estão relacionados à elevada produção de escuma, à baixa sedimentabilidade do lodo, à baixa resistência a choques de carga, às dificuldades na remoção de nutrientes (nitrogênio e fósforo) e aos problemas na degradação de gorduras, óleos e outros tipos específicos de poluentes, como corantes (CAMMAROTA et al., 2003).

Assim, a utilização de águas residuárias de laticínios na agricultura têm surgido como uma alternativa para controle da poluição das águas superficiais e subterrâneas, além da disponibilização de água e fertilizantes para as culturas, ciclagem de nutrientes e aumento na produção agrícola, reduzindo os custos de produção e melhorando as características físicas, químicas e microbiológicas do solo (CAVALCANTI, 2012).

Todavia, o uso incorreto pode trazer efeitos deletérios tanto ao solo quanto às culturas. A taxa de aplicação de águas residuárias deve estar baseada no nutriente que estiver em maior concentração relativa e na quantidade deste nutriente requerido pela cultura, pois, caso esses níveis sejam suplantados, além de comprometer a produtividade da cultura, podem provocar degradação do solo e das águas superficiais e subterrâneas (MATOS, 2014).

As principais alterações descritas para os solos que recebem águas residuárias se resumem aos efeitos sobre o carbono e nitrogênio totais, atividade microbiana e N-mineral, cálcio e magnésio trocáveis, salinidade, sodicidade e dispersão de argilas (FONSECA et al., 2007). Em resumo, a disposição de águas residuárias no sistema solo-planta, quando feita sem critérios agronômicos e ambientais, pode causar problemas de infiltração de água no solo, de contaminação do solo, das águas superficiais e subterrâneas e de toxicidade às plantas (ERTHAL et al., 2010). 
De acordo Larcher (2006), o valor máximo de $\mathrm{Na}^{+}$absorvido pelas plantas em habitat halófito é de $150 \mathrm{~kg} \mathrm{ha}^{-1} \mathrm{ano}^{-1}$. Embora estudos sobre o aproveitamento agrícola de diversos tipos de águas residuárias já tenham sido realizados, pouco se conhece a respeito das doses a serem aplicadas da água residuária de laticínios. Sendo importante considerar o $\mathrm{Na}^{+}$como elemento químico referencial, de forma a não comprometer a qualidade química e física do solo, fazendo com que, dessa forma, a prática de aproveitamento da água residuária seja agronômica e ambientalmente sustentável.

Sabendo-se que o processo de sanilização e sodificação dos solos é um problema que vem se acentuando em várias partes do mundo e que o efluente de laticínio tem grande presença de sais, objetivouse, avaliar o impacto no solo, em relação ao índice de saturação por sódio, onde a saturação por sódio indica a proporção de sódio solúvel em relação à CTC total do solo.

\section{MATERIAIS E MÉTODOS}

O trabalho foi conduzido no Instituto Federal Goiano - Campus Urutaí (IF Goiano), em Urutaí - GO, localizado a $17^{\circ} 29^{\prime} 6^{\prime \prime} S, 48^{\circ} 12^{\prime} 27^{\prime \prime} \mathrm{O}$ e altitude de $712 \mathrm{~m}$. Segundo a classificação de Köppen, o clima da região é do tipo Cwa, caracterizado como úmido tropical com inverno seco e verão chuvoso, com precipitação e temperatura médias, anuais, de $2000 \mathrm{~mm}$ e $28^{\circ} \mathrm{C}$ (SILVA, 2015).

Para condução do experimento, foram coletadas amostras de solo da área experimental nas camadas de 0-10, 10-20, 20-30 e 90-100cm, conduzidas ao Laboratório de Pesquisa e Análises Químicas, do Instituto Federal Goiano - Campus Urutaí, para determinação das características químicas conforme metodologias descritas em EMBRAPA (1997), sendo classificado como Latossolo Vermelho Distrófico Típico. Na Tabela 1, estão apresentadas as características químicas do solo utilizado nos ensaios experimentais.

Tabela 1: Caracterização química do solo presente na área experimental nas diferentes camadas.

\begin{tabular}{|c|c|c|c|c|c|c|c|c|c|c|}
\hline \multirow[t]{2}{*}{ Prof. } & $\mathrm{pH}$ & $\mathrm{P}$ & $\mathrm{K}$ & $\mathrm{Ca}$ & $\mathrm{Mg}$ & $\mathrm{Na}$ & $\mathrm{Al}$ & $\mathrm{H}+\mathrm{Al}$ & MOS & SB \\
\hline & & \multicolumn{5}{|c|}{$\mathrm{mg} \mathrm{dm}^{-3}$} & \multicolumn{2}{|c|}{$\mathrm{cmol}_{\mathrm{c}} \mathrm{dm}^{-3}$} & $\mathrm{~g} \mathrm{~kg}^{-1}$ & $\mathrm{cmol}_{\mathrm{c}} \mathrm{dm}^{-3}$ \\
\hline $0-10$ & 4,99 & 0,00 & 0,00 & 0,22 & 0,50 & 4,04 & 0,20 & 4,62 & 21,32 & 0,74 \\
\hline $10-20$ & 5,04 & 0,00 & 0,00 & 0,22 & 0,53 & 4,48 & 0,20 & 3,46 & 14,44 & 0,78 \\
\hline $20-30$ & 5,19 & 0,00 & 0,00 & 0,21 & 0,42 & 4,05 & 0,10 & 3,63 & 17,19 & 0,66 \\
\hline $90-100$ & 5,18 & 0,00 & 0,00 & 0,28 & 0,55 & 4,73 & 0,20 & 3,30 & 17,19 & 0,86 \\
\hline
\end{tabular}

Onde: $\mathrm{pH}$ - potencial hidrogeniônico, $\mathrm{P}$ - fósforo Total, $\mathrm{K}$ - Potássio total, $\mathrm{Ca}$ - cálcio total, $\mathrm{Mg}$ - Magnésio total, $\mathrm{Na}$ sódio total, Al -acidez trocável, $\mathrm{H}+\mathrm{AL}$ - acidez potencial, MOS - matéria orgânica e SB-Soma de base.

Após o preparo do solo, sementes de capim-mombaça foram lançadas à mão na proporção de 15 kg de sementes por hectare, rastelando-se posteriormente o solo, de modo que as sementes ficassem à uma profundidade de 3 a $5 \mathrm{~cm}$. Após a germinação das sementes e do primeiro corte de nivelamento aos 70 dias após semeio (DAS), foram delimitadas 20 parcelas experimentais de $9 \mathrm{~m}^{2}$ cada ( $3 \mathrm{~m} \times 3 \mathrm{~m}$ ) com bordaduras de $1 \mathrm{~m}$, separadas por ruas de $0,70 \mathrm{~m}$.

Para repor a demanda evapotranspirométrica da cultura a cada dois dias, determinada a partir de dados meteorológicos obtidos por meio de uma estação automática instalada próxima à área experimental, utilizou-se o sistema de irrigação por pivô central. O solo foi cultivado com capim-mombaça para poder avaliar a absorção do sódio pelas raízes, sendo a escolha da cultura em virtude de sua maior exigência por 
solo fértil, profundo, bem drenado, clima quente e precipitação superior a $1000 \mathrm{~mm}$ ano-1 (JANK, 2008), condições semelhantes àquelas encontradas na área de estudo.

Os ensaios experimentais foram constituídos por quatro dosagens de sódio presentes na água residuária de laticínios, devido a maior concentração relativa desse nutriente. Os tratamentos foram compostos por água residuária de laticínios fornecendo T1 - $75 \mathrm{~kg} \mathrm{ha}^{-1} \mathrm{de} \mathrm{Na}^{+}, \mathrm{T} 2$ - $150 \mathrm{~kg} \mathrm{ha}^{-1} \mathrm{de} \mathrm{Na}^{+}, \mathrm{T} 3$ $300 \mathrm{~kg} \mathrm{ha}^{-1}$ de $\mathrm{Na}^{+}$, T4 - $600 \mathrm{~kg} \mathrm{ha}^{-1}$ de $\mathrm{Na}^{+}$e, T5 - tratamento controle, em quatro repetições, em delineamento inteiramente ao acaso, sendo as laminas aplicadas sobre as folhas com uso de um regador.

As águas residuárias utilizadas foram disponibilizadas por uma agroindústria situada no município de Orizona, sendo transportadas semanalmente até o IF Goiano, acondicionadas em reservatório de $500 \mathrm{~L}$ e determinadas características físico-químicas conforme metodologias recomendadas pela APHA (2012) antes de serem aplicadas no solo. Na Tabela 2 estão apresentadas as características da água residuária utilizada nos ensaios experimentais.

Tabela 2: Caracterização físico-química das amostras dos efluentes de laticínios utilizados nos ensaios experimentais

\begin{tabular}{|c|c|}
\hline Parâmetros & Valores \\
\hline Temperatura (으) & $29,60 \pm 0,50$ \\
\hline $\mathrm{pH}$ & $4,70 \pm 0,70$ \\
\hline Sódio total (mg L-1) & $2534,70 \pm 509,91$ \\
\hline Condutividade Elétrica $\left(\mu \mathrm{S} \mathrm{cm}^{-1}\right)$ & $2.025,50 \pm 607,30$ \\
\hline Sólidos totais $\left(\mathrm{mg} \mathrm{L}^{-1}\right)$ & $6.333,00 \pm 1.195,00$ \\
\hline Sólidos em suspensão - totais (mg L-1) & $767,00 \pm 456,50$ \\
\hline Sólidos sedimentáveis $\left(\mathrm{mL} \mathrm{L}^{-1}\right)$ & $28,00 \pm 9,50$ \\
\hline Turbidez (UNT) & $1.104,00 \pm 313,9$ \\
\hline $\mathrm{DQO}\left(\mathrm{mg} \mathrm{O}_{2} \mathrm{~L}^{-1}\right)$ & $8.437,00 \pm 1.536,0$ \\
\hline $\mathrm{DBO}_{5}\left(\mathrm{mgO}_{2} \mathrm{~L}^{-1}\right)$ & $3.374,80 \pm 952,0$ \\
\hline Nitrogênio total (mg L-1) & $115,50 \pm 31,04$ \\
\hline Fósforo total $\left(\mathrm{mg} \mathrm{L}^{-1}\right)$ & $393,35 \pm 74,50$ \\
\hline Potássio total ( $\left.\mathrm{mg} \mathrm{L}^{-1}\right)$ & $218,56 \pm 11,71$ \\
\hline Cálcio total $\left(\mathrm{mg} \mathrm{L}^{-1}\right)$ & $41,43 \pm 7,33$ \\
\hline Magnésio Total (mg L-1) & $184,39 \pm 53,85$ \\
\hline $\operatorname{RAS}\left(\left(\mathrm{mmolc} \mathrm{L}^{-1}\right)^{1 / 2}\right)$ & $23,90 \pm 8,66$ \\
\hline Coliformes Totais (NMP $100 \mathrm{~mL}^{-1}$ ) & $2,42 \pm 10^{9}$ \\
\hline Coliformes Termotolerantes (NMP $100 \mathrm{~mL}^{-1}$ ) & $7,70 \pm 10^{5}$ \\
\hline
\end{tabular}

$\mathrm{pH}$ - potencial hidrogeniônico, DQO - demanda química de oxigênio, DBO - demanda bioquímica de oxigênio, RAS relação de adsorção de sódio.

Após segundo corte de nivelamento no capim, ocorrido aos 110 dias após semeadura (DAS), iniciou a aplicação das diferentes lâminas de água residuária em três períodos com intervalos quinzenais (155, 170, 185 dias após a semeadura). No dia seguinte à aplicação, amostras de solo foram coletadas nas camadas 010, 10-20, 20-30 e 90-100 cm, para caracterização química, conforme metodologias descritas em EMBRAPA (1997). Para monitorar o efeito do efluente ao longo do tempo, também foram coletadas amostras de solo decorridos dois meses (245 DAS) e cinco meses (335 DAS) após finalização das aplicações de água residuária do laticínio.

Os dados foram submetidos às análises de variância, sendo as médias comparadas utilizando-se o teste de Tukey a $5 \%$ de probabilidade. Os modelos de regressão foram escolhidos com base na significância dos coeficientes de regressão, aplicando-se o teste t num nível de até $10 \%$ no coeficiente de determinação e no processo em estudo, e utilizou-se o programa estatístico SAEG 9.1 (2006). 


\section{RESULTADOS E DISCUSSÃO}

Salinidade, na forma de $\mathrm{Na}^{+}$, pode afetar diretamente as propriedades do solo, por meio de fenômenos conhecidos por floculação e dispersão, podendo concorrer para significativa diminuição na condutividade hidráulica do solo (TOZE, 2006). Na Figura 3 está apresentada a variação do índice de saturação por sódio (ISNa) em função da profundidade do solo e do tempo, nos solos submetidos aos diferentes tratamentos.

Pode-se observar, na Figura 1, que no solo de todos os tratamentos, o ISNa apresentou relação quadrática com a profundidade e com o tempo. Possivelmente, as aplicações das diferentes doses do efluente de laticínio e de água de irrigação, além da maior densidade de raízes foram responsáveis pela maior concentração do ISNa nas camadas superficiais.
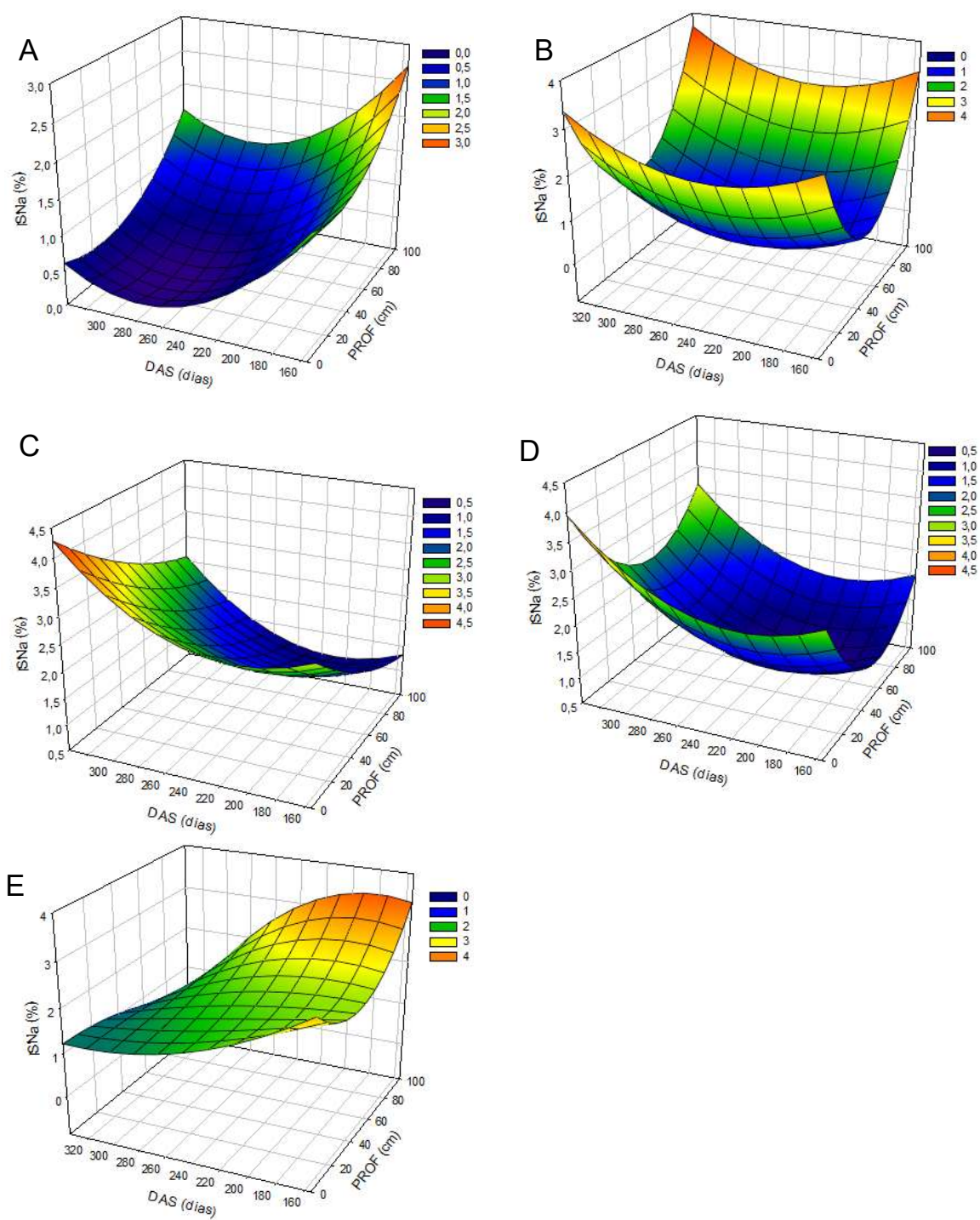

Figura 1: Variação nos valores de índice de saturação por sódio (ISNa), em função da profundidade (PROF) e dias após o semeio (DAS), nos solos submetidos aos tratamentos 1 (A), 2 (B), 3 (C), 4 (D), e 5 (E).

Desse modo, o efeito quadrático em relação a profundidade pode ter sido decorrente do aporte de sais pela fertirrigação do efluente de laticínio, sendo incorporado pela cultura nas camadas medianas e percolado após esses perfis pela água das chuvas para as camadas mais profundas.

Por outro lado, em relação ao efeito quadrático do tempo pode ter sido decorrente da lixiviação 
resultante da água das chuvas, que corresponde ao DAS 245 que coincide com o período chuvoso, segundo Rodrigues et al. (2007), devido a fatores climáticos, a condições edáficas e aos métodos de irrigação, os sais dissolvidos na água podem se acumular no perfil do solo ou se deslocar pela solução pelos perfis, o que pode explicar o comportamento encontrado.

Observa-se, ainda, que o maior valor de ISNa foi obtido nos solos testemunha $(0,20 \mathrm{~m}$ da superfície, aos 171 DAS), contrariando a pressuposição de que a fertirrigação com água de laticínios contribuiria significativamente para elevação da salinidade. Todavia, conforme Cabello (1990), valores de ISNa inferiores a 7\%, em geral, não causam problemas de dispersão de argilas, o que pôde ser confirmado pelas análises de dispersão de argilas realizadas paralelamente as do ISNa, cujo valor máximo obtido foi 1,44\% em solos submetidos ao T1, que por sua vez não apresentaram problemas na infiltração de água no solo.

\section{CONCLUSÕES}

No sistema estudado, grande parte do $\mathrm{Na}^{+}$foi absorvido pela cultura ou lixiviada e uma pequena parte foi acumulada nos solos. Isso se deu ao fato de que os sais são depositados na zona radicular e acabaram por serem absorvidos pelo capim-mombaça, não sendo suficiente para aumentar de modo prejudicial o ISNa e mantendo assim a qualidade dos solos estudado.

Apesar da recomendação existente de aplicação de no máximo $150 \mathrm{~kg}$ de $\mathrm{Na}^{+}$por hectare, esta pesquisa concluiu que nas condições e solo abordados, o efluente de laticínios pode ser utilizado na fertirrigação de capim-mombaça com taxa de aplicação de até $600 \mathrm{~kg} \mathrm{ha}^{-1} \mathrm{de} \mathrm{Na}^{+}$, levando em consideração a sanilização e sodificação do solo.

Trata-se, portanto, de uma nova sugestão para aplicação de efluente de laticínios, aumentando-se a quantidade de $\mathrm{Na}^{+}$a ser aportada ao solo, o que reduz a quantidade de área necessária para o tratamento do efluente por disposição no solo.

AGRADECIMENTOS: Ao apoio financeiro concedido pelo Instituto Federal Goiano Campus Urutaí e a PROPPI.

\section{REFERÊNCIAS}

APHA. American Public Health Association. Standard Methods for the Examination of Water and Wastewater. 22 ed. New York: APHA, 2012.

APHA. American Public Health Association. Standard methods for the examination of water and wastewater. 20 ed. Washington: APHA, 1998.

BRAILE, P.M.; CAVALCANTI, J. E. W. A.. Manual de tratamento de águas residuárias industriais. São Paulo: CETESB, 1993.

CABELLO, F. P.. Riegos localizados de alta frequência: goteo, microaspersion e exudacion. Madrid: Mundi Prensa, 1990.

CAVALCANTI, J. E. W. A.. Manual de tratamento de efluentes industriais. 2 ed. São Paulo: Engenho Técnica, 2012.
CAMMAROTA, M. C.; FREIRE, D. M. G.. A review on hydrolytic enzymes in the treatment of wastewater with high oil and grease content. Bioresource Technology, New York, v.97, n.17, p.2195-2210, 2006.

CATÃO, R. M. C.; CEBALLOS, B. S. O.; KONIG, A.; FEIJÓ, V. S. G.. Bactérias do gênero Listeria em águas residuárias do processamento do leite. In: SIMPÓSIO LUSO-BRASILEIRO DE ENGENHARIA SANITÁRIA E AMBIENTAL, 9. Anais. Porto Seguro: ABES, 2000.

EMBRAPA. Centro Nacional de Pesquisa de Solos. Manual de métodos de análise de solo. 2 ed. Rio de Janeiro: EMBRAPA, 1997.

ERTHAL, V. J. T.; FERREIRA, P. A.; MATOS, A. T.; PEREIRA, O G.. Alterações físicas e químicas de um Argissolo pela 
aplicação de água residuária de bovinocultura. Revista Brasileira de Engenharia Agrícola e Ambiental, v.14, n.5, p.467-477, 2010.

FONSECA, A. F.; HERPIM, U.; PAULA, A. M.; VICTÓRIA, R. L.; MELFI, A. J.. Agricultural use of treated sewage effluents: Agronomic and environmental implications and perspectives for Brazil. Scientia Agrícola, v.64, n.2, p.194-209, 2007

LARCHER, W.. Ecofisiologia vegetal. São Carlos: Rimas Artes e Textos, 2006

MATOS, A. T.. Tratamento e aproveitamento agrícola de resíduos sólidos. Viçosa: UFV, 2014.

RODRIGUES, J. O.; ANDRADE, E. M.; CRISÓSTOMO, L. A.; TEIXEIRA, A. S.. Modelos da concentração iônica em águas subterrâneas no Distrito de Irrigação Baixo Acaraú. Revista Ciência Agronômica, v.38, n.4, p.360-365, 2007.

SARAIVA, C. B.; MENDONÇA, R. C. S.; SANTOS, A. L. S.; PEREIRA, D. A.. Consumo de água e geração de efluentes em uma indústria de laticínios. Rev. Inst. Latic. "Cândido Tostes", v.367/368, n.64, p.10-18, 2009

TOZE, S.. Reuse of effluent water--benefits and risks. Agricultural Water Management, v.80, n.1-3, p.147-159, 2006.

VOURCH, M.; BALANNEC, B.; CHAUFER, B.; DORANGE, G.. Treatment of dairy industry wastewater by reverse osmosis for water reuse. Desalination, Orlando, v.219, p.190-202, 2008.

A CBPC - Companhia Brasileira de Produção Científica (CNPJ: 11.221.422/0001-03) detém os direitos materiais desta publicação. Os direitos referem-se à publicação do trabalho em qualquer parte do mundo, incluindo os direitos às renovações, expansões e disseminações da contribuição, bem como outros direitos subsidiários. Todos os trabalhos publicados eletronicamente poderão posteriormente ser publicados em coletâneas impressas sob coordenação da Sustenere Publishing, da Companhia Brasileira de Produção Científica e seus parceiros autorizados. Os (as) autores (as) preservam os direitos autorais, mas não têm permissão para a publicação da contribuição em outro meio, impresso ou digital, em português ou em tradução. 